\title{
A CONTRIBUTION TO THE BUILT HERITAGE ENVIRONMENTAL IMPACT ASSESSMENT
}

\author{
R. Žarnić ${ }^{\mathrm{a} *}$, V. Rajčić ${ }^{\mathrm{b}}, \mathrm{N}$. Skordaki ${ }^{\mathrm{a}}$ \\ ${ }^{\text {a }}$ University of Ljubljana, Faculty of Civil and Geodetic Engineering, Jamova 2, 1000 Ljubljana, Slovenia \\ roko.zarnic@fgg.uni-lj.si,nikoletta.skordaki@,fgg.uni-lj.si \\ ${ }^{\mathrm{b}}$ University of Zagreb, Faculty of Civil Engineering, Kačićeva 26, 10000 Zagreb, Croatia, vrajcic@grad.hr
}

KEY WORDS: Heritage asset, Data base, EU CHIC, Environmental impact, Structure of heritage building

\begin{abstract}
:
The understanding and assessment of environmental impact on heritage assets is of the highest importance for heritage preservation through well-organized maintenance based on proper decision-making. The effort towards development of protocol that would enable comparison of data on heritage assets in Europe and Mediterranean countries was done through EU Project European Cultural Heritage Identity Card. The special attention was paid to classification of environmental and man-induced risks to heritage. In the present paper the idea of EU CHIC is presented. Environmental risks are discussed in context of their influence on structure of heritage buildings that are exposed to sudden environmental impacts.
\end{abstract}

\section{INTRODUCTION}

Due to historic reasons Europe has rich cultural heritage that reflects development and decline of civilizations. The collective memory of inhabitants is embedded in built heritage assets and provides enormous economic opportunities in additional income, creation of highly qualified jobs and building the basis for regional identity.

Built cultural heritage is at constant risk due to environmental and man-induced impacts. The deterioration of vital parts of built heritage due to environmental impact augmented by climate changes increase theirs vulnerability to sudden natural events. Human activities on one side contribute to risks and on other side mitigate them.

The first step of mitigation is learning about environmental influences to understand their impact on heritage assets. Understanding is based on relevant data that should be adequately collected, processed and stored using the proper protocols that are commonly developed by experts on multidisciplinary basis. The novel protocols assist the integration of maintenance decision making in the management procedures to improve sustainable uses of cultural assets. By the enhanced maintenance, the economic value of built heritage assets is increased. Their contemporary use is strengthened and significantly contributes to sustainable development of communities.

The innovative emerging technologies (high resolution digital cameras, thermal imaging cameras, GPS controlled drone platforms etc.) are of crucial importance for collection of reliable data. They enable rapid IT supported inspection, documentation and permanent follow-up of built heritage changing in the fourth, time dimension.

\section{INTERNATIONALY DEVELOPED DATA BASES}

\subsection{A Need for Internationally Comparable Data}

In many countries there are well-established systems and tools used for inventory and documentation of the cultural heritage. The tradition in care for cultural heritage reflects in them and the local approaches and understandings are basis for their approach to content. In some countries there are several systems for data collection, which are not connected together. Therefore, the strait comparison of data on heritage assets is not possible.
The overview of currently used approaches in seven countries (Croatia, Czech Republic, Greece, Israel, Italy, Poland and Slovenia) was presented during the 1st EU-CHIC Workshop held in Vienna on April 292010 (Žarnić et al., 2012). The Ad hoc group for Inventory and Documentation within the Technical Co-operation and Consultancy Programme related to the Integrated Conservation of the Cultural Heritage contributed the most complete effort in harmonization of approaches on at least basic level in form of three standards related to historic buildings, monuments, archaeological sites and heritage objects (Guidance, 2009).

In order to contribute to development of internationally recognized protocols for data collection the experts from fourteen European countries, Israel and Egypt joint their efforts in development of model for so-called Cultural Heritage Identity Card (www.eu-chic.eu). It has been developed within the EU financed Coordinated Action EU-CHIC (FP7-ENV2008-1 no. 226995, 2009/12).

The idea of Identity Card originates from the COST Action C5: "Urban Heritage-Building Maintenance", 1996-2000 (Hofmann et al., 2002). The general conclusion stressed in final report was that there is a serious lack of reliable data on European urban heritage and a pressing need to collect it, in order to support the on-going process of refurbishment of existing buildings. COST C5 Action concluded that there are great variations in the systems of establishing and evaluating data from buildings in the European countries. The responsibility for collecting data depends on the administrative structure in each country. Planning of broad activities, such as preventive strengthening or even post-earthquake measures in European earthquake prone areas, or energy preservation measures, can be better based on mutually developed methodology. The basic rules and approach can be developed from the existing European standards and codes. However, no generally accepted approach existed that would lead to European methodology.

The creation of pan-European protocol for data collection is just a first step in the more ambitious process. The essential part of data in this protocol is related to identification of risks to which heritage assets are exposed. It is well known that the vulnerability of assets is one of main criteria for intervention in asset in order to increase its resilience. The final aim of process is to develop a general approach to resilience assessment of heritage assets based on identification of risks that can be generalized by introduction of risk indicators. 


\subsection{European Cultural Heritage Identity Card (EU-CHIC)}

The main objective of the EU CHIC Project was to develop and test guidelines that are required for the efficient compilation and storage of data pertinent to each asset under observation. Data can be collected and well maintained only if the appropriate protocols are developed and applied. The documentation protocol can be understood as an envelope with set of rules, which establish and define the categories of data needed for achievement of targeted goal. If protocol is set in general way it can be used for collection and processing of different types of data. In case of protocol for cultural heritage it can be applied to build heritage, to archaeological sites, to cultural landscape, to heritage objects and to collections of artefacts. Protocol can be composed of several layers regarding the type of data their amount and nature. During their lifetime the heritage assets have been constantly exposed to external natural influences that caused the material and structure decay processes and to alternations of use and interventions in their structure. The necessary data for evaluation of consequences of events in assets lifetime can be collected from different sources and documents but the on-site inspection is the only way to assess the current state of asset. From assessment of asset under observation and knowledge gained from studying of similar cases the prediction of future behaviour can be estimated. The important data for estimation, besides ones collected by inspection, are risks of events that may happen in future life of asset. The sufficient amount and reliability of data is necessary background for decision-making that determines and thus influence the future life of asset. Those who are responsible for asset should always be ready to answer to the simple question: "What will be the consequences of their decisions?"

The collecting of detailed data on cultural heritage assets engage a significant amount of efforts of professionals and researchers what means also engagement of significant amount of funds. Therefore, the owners or responsible organization of authority has a property rights and can exploit data following their needs. However, a certain amount of data should be given to the interested public for general use (research, education, tourism etc.). On other side, the sensitive data that are under owners' control are needed for management and all other decisions related to ownership of asset.

As an answer to these dilemmas, the new structure of data has been developed. It was visualized in form of iceberg and named "EU CHIC Iceberg" or in shorter form "Chicberg" (Figure 1).

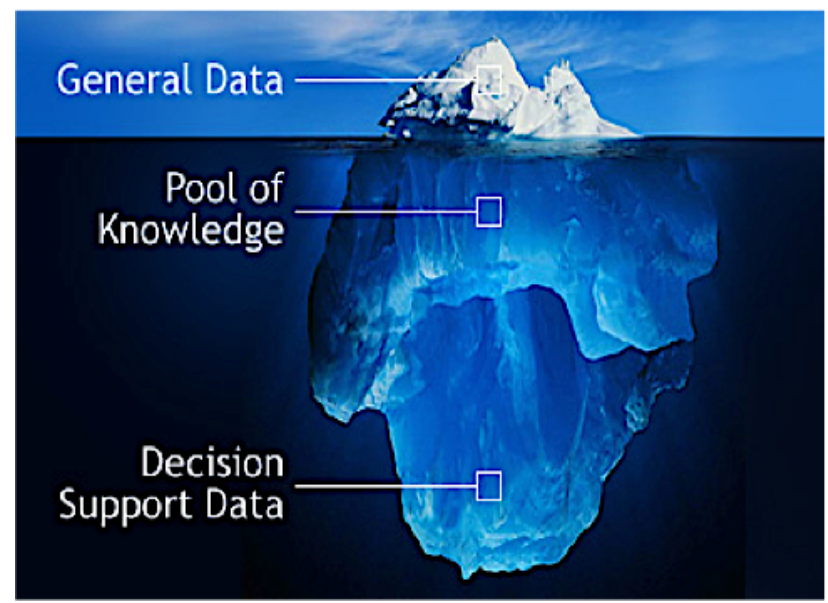

Figure 1. The scheme of CHICBERG

Data, that in their total volume create the Identity Card, are divided in two groups (Table 1). The "upper" group of data are open to general, public use. The "lower" two groups of data are the sensible ones and of high value for owner of asset. Therefore, they can be used only upon their permission.

Following this scheme the Cultural Heritage Identity Card is not a single document of asset but a set of documents that contains comprehensive information and that are created and updated due entire lifetime of asset. The updating follows the changes of asset after the initial creating of files. Therefore the system of three levels is established as presented in Table 1. The first level of the Card contains data collected mainly from publically available sources with additional information about current physical condition and major risks to which asset may be exposed. The original intention of the Card was to establish a system that will enable comparison between the assets of same type across the Europe and Mediterranean countries. The first level of the Card is designed to meet this goal.

\begin{tabular}{|c|c|}
\hline \multicolumn{2}{|c|}{ PUBLIC DATA } \\
\hline \multicolumn{2}{|c|}{ General Data obtained by Identification } \\
\hline $\begin{array}{c}\text { Name, location, legal status, type, dating, function, major } \\
\text { risks, materials, structure, state of conservation }\end{array}$ \\
\hline \multicolumn{2}{|c|}{ OWNER CONTROLLED DATA } \\
\hline Detailed Information on the Cultural Heritage Asset \\
\hline Non-physical Aspects & Physical Aspects \\
\hline History & Geospatial aspects \\
Art history & Risks \\
Sociology & Archaeology \\
Ethnology & Architecture \\
Cultural landscape & Materials \\
Legal issues & Structure \\
Economical issues & Movable objects \\
Previous interventions & Current condition \\
Conservation & Energy efficiency \\
Valuation methods & Surveying techniques \\
\hline \multicolumn{2}{|c|}{ Decision Support: } \\
Knowledge implementation procedures \\
Intervention decision making \\
Decision impact analysis \\
Site management \\
\hline
\end{tabular}

Table 1. The content of the Cultural Heritage Identity Card

The existing standards form an important, well-established system and the intention of EU CHIC is not to compete or replace it but to integrate them to wider and more ambitious system. The first level of the Card is meant as an introduction to lower, more important levels because the basic information about asset given in the first level is elaborated in detail in the second level named Pool of Knowledge. The structured knowledge, as presented in Table 1, is a basis for the most important aim of system: support to decision making that is of crucial importance for preservation of cultural heritage asset. One of most important issues is prevention of heritage asset from the risks. Risks can be identified from past events in area of heritage asset location but also from the scientific prediction of potential harmful events. The variety of risks and concurrency of events can be managed by introduction of risk indicators that enable good prediction of influences even when the amount of reliable data is not sufficient

Major risks may be divided in two categories regarding their source: environmental and man-induced or anthropogenic-social ones (Table 2). 
The environmental risks are either the long-term impacts or sudden events. The long-term impacts are expressed in term of the environmental factors, which affect the asset and the results appeared after a long period of time. Sudden environmental impacts expressed in terms of events, which affect the asset in relatively, short time interval (measured in minutes or at most in hours) and which time of occurrence could not be foreseen in advance. The anthropogenic impacts that might be the consequence of regular economic activities and other unintended sources of harmful influence to heritage asset or the consequence of intended harmful influences. Among the most dangerous and relatively frequent unintended influences are improper decisions because of lack of knowledge or data that is a serious reason for wrong reaction of responsible persons.

Therefore, the key target of EU-CHIC Protocol is its' support to decision making procedures. The third part of "Chicberg" is oriented to exploitation of knowledge collected in the core of Identity Card. Available data collected in the second section should be organized in a way that makes them suitable for various purposes of management as are: intervention decisionmaking, decision impact analysis and site management.

A good example is usage of data for the regular monitoring and inspection of historic buildings and monuments as developed and applied by the "Monumentenwacht" organization in the Netherlands (http://www.monumentenwacht.nl/home) and in Flanders Region of Belgium.

\begin{tabular}{|l|l|}
\hline \multicolumn{2}{|c|}{ ENVIRONMENTAL RISKS } \\
\hline A: Long term influences & B: Sudden events \\
\hline A1: Bio-attack & B1: Wind storm \\
A2: Climate conditions fluctuations & B2: Fire \\
A3: Aeolic impact & B3: Flood \\
A4: Water (Atmospheric, Ground) & B4: Earthquake \\
A5: Solar radiation & B5: Landslide \\
A6: Particle matter \& aerosols & B6: Avalanche \\
A7: Long term loading & B7: Tsunami \\
A8: Geological conditions & B8: Volcano \\
(including local particularities) & \\
\hline \multicolumn{2}{|c|}{ ANTHROPOGENIC - SOCIAL RISKS } \\
\hline C: Unintended influences & D: Intended events \\
\hline C1: Economic activities & D1: Vandalisms \\
C2: Accidental events & D2: Riots \\
C3: Improper decisions & D3: Wars \\
\hline
\end{tabular}

Table 2. List of risks to which the heritage assets are exposed

Decision-making can be easier if experiences gained from successful cases can be exchanged and compared. The EUCHIC aims to contribute to simplification of comparison of general data on heritage assets and to international exchange of knowledge and experiences gained from heritage preservation. It may be also a basis for development of pan-European system of regular monitoring, inspection and maintenance of historic buildings, monuments and sites.

Preservation of cultural heritage is related with high costs and required interventions generally exceed available funding. It is, therefore, necessary to prioritise renovation interventions. Multi-criteria assessment can lead to scientifically sound and informed decisions about interventions. The research carried out with the purpose of establishing a multi-criteria method for the assessment of architectural heritage is under progress in Slovenia. In (Vodopivec et al., 2014) is explained the methodology used to develop the multi-criteria method. Its main elements are critical content analysis of relevant literature, comparative analysis between the Slovenian and international space, and identification of relevant criteria and sub-criteria of the decision method. The course and results of empirical research, based on interviews with selected experts, is presented together with the results of the criteria importance ranking based on the Analytic Hierarchy Process (AHP) method. The research presented in the paper is interdisciplinary and brings together tangible and intangible aspects of cultural heritage. The obtained results confirm that rational determination of relative importance of individual criteria for the assessment of architectural heritage can help decision-makers to identify buildings with higher refurbishment priority.

\section{ENVIRONMENTAL IMPACT}

\subsection{Long-term environmental factors}

Interest of researchers involved in heritage preservation resulted in relatively reach number of published papers, although all aspects are not covered equally. The following brief reviewed is organized to follow eight EU-CHIC identified long-term influences in order to comment their potential impact on structural properties of heritage buildings.

A1. Bio-attack: Microorganisms activity has a significant impact to historic building and monuments. Depending on climate conditions a variety of organisms like fungi, algae, bacteria, lichens etc. can be developed on or/and into the surface and colonize it. The decays that can be caused are the creation of biofilm on the surface, chemical corrosion, aesthetic problems including discoloration and exfoliation as well as physical damage such as penetration into the material, resulting rise of the internal pressure and detachment of the surface parts as well as failure of materials' components (Scheerer et al, 2009; Gaylarde et al, 2003).

A2. Climate conditions fluctuations: Climate conditions play a significant role to cultural heritage and therefore any longterm or even seasonal climate fluctuations affect the condition of historic buildings and monuments in causing or accelerating aesthetic and mechanical decays. The climatic fluctuations are mainly concerned changes and more particularly an increase in the temperature, water (relative humidity) and power of the wind. Depending on each region climate (Mediterranean, moderate, dry etc.) changes of the above weather agents can contribute to monuments' deterioration. An increase of temperature can lead to drier summers and hence to bigger exposure to sunlight. In parallel an increase of the relative humidity prolongs the wetting time on buildings' surface, which might cause a development of microorganisms, saturation of the surface and deposition of more particles on the surface. Last but not least, strong winds transfer more particles for longer distances on the surface and also contribute to the deeper penetration of rainwater into the buildings envelope. Climate fluctuations cause a variety of weathering to historic buildings and monuments including aesthetic deterioration (loss of artistic details on the surface), cracks and erosion, whereas they can affect the surrounding environment like the soil and foundations causing structural problems (Brimblecombe et al, 2011; Bonazza et al, 2009).

Understanding the climatic influence on materials and structural components is especially important in the current era of dramatic climatic changes. There are not initiating only short tem events as storms, floods and other natural disasters but also accelerate the development of damages due to long-term influences (EU FP7 project Climate for Culture). 
A3. Aeolic impact: Aeolic agents, which affect mostly the built Cultural Heritage, are wind velocity, power and direction. Surfaces exposed to the aeolic impact suffer from abrasion and shear stress. Damages caused by grits, sand etc. that are lifted from the surrounding area because of the wind and hit the monuments' surface are also observed. The aeolic impact causes wind erosion, cracks, material loss and detachment of building's parts, like roof tiles, whereas its interaction with rainwater can lead to serious decay (facilitation of water's penetration in materials) (Feilden, 2003; Hussein et al, 2009).

A4. Water (Ground, Atmospheric): Water is considered as an important weathering factor for historic buildings and monuments. It can reach building's surface through the atmosphere (sea spray, rain) and through the ground (rising damp). Water is a carrier of soluble salts and therefore when it penetrates into the surface, it reaches materials porous. Soluble salts exert pressure to the pores, causing decay to the buildings materials such as efflorescence, loose of the material, peeling, cavitation etc. (Feilden, 2003; Karoglou et al, 2005). Seawater and acidic rainwater may cause significant decays to materials like cast iron with the convention of the iron to insoluble iron oxide (oxidation and galvanic corrosion) and loss of iron components (US-GSA).

A5. Solar radiation: Solar radiation affects the built cultural heritage either directly (surfaces are exposed direct to insolation) or indirectly (reflected sunlight from surrounding building, trees etc.). Depending of its physicochemical properties each material can absorb and reflect specific sunlight wavelengths (visible, infrared, ultraviolet). The solar radiation can cause aesthetic problems to materials, such bleaching of coloured stones, whereas in materials like wood sunlight can cause fading and brittleness (Feilden, 2003; Harrell et al, 2007).

A6. Particle matter \& aerosols: The terms particulates and aerosols include the solid particles (e.g. dust, soot, grit, sand, SOx, NOx), which are suspended in the atmosphere. Particle matter originates from combustion fuels, vehicle exhausts, industrial activity and they are an often phenomenon in urban and industrial areas, where the air pollution is among others a major problem for the condition of monuments and historic buildings. Other climatic conditions can facilitate the decay caused by particles. For example due to prevailing winds they can travel to the atmosphere, reach buildings' surface, deposit on it and react with the materials' components (e.g. gypsum of stone monuments). Therefore decay patterns such as formation of crusts; detachment, pitting, color alterations and granular disintegration are observed (Moropoulou et al, 1998; Maravelaki-Kalaitzaki, 2005; Feilden, 2003).

A7. Long-term loading: Structural elements of heritage buildings and buildings as whole are for centuries loaded by gravity load that influence the condition of materials due to their rheological properties (especially in cases of wood and masonry material). Any other of here discussed factors may additionally contribute to deterioration processes that consequently increase the effect of long-term loading. Periodically environmental actions (low intensity earthquakes, strong winds, heavy traffic vibrations, church bells) induce dynamic loading which result in limited damages. Accumulation of damages due to constant vertical loading and different sporadic loading results in various damages of structural elements and weakens their resistance to intense sudden events as strong earthquakes, floods, windstorms etc. In combination with bad geological conditions and ground water action the long-term loading may initiate partial or total collapse of building. Well know a case is the 1989 collapse of the $11^{\text {th }}$ century Civic Tower in Pavia, Italy (Anzani et al., 2000).

A8. Geological conditions (including local particularities): This environmental factor refers to the geo-environmental conditions, which can affect historic buildings and monuments. This category includes tectonic activity and geological formations of the surrounding area including type of soil, rocks, underground water, and slopes. Ground instability, slope movements, settlement, ground water activity and erosion processes that lead to rock falls, loose of rock mass, cracks and fractures are among the most detrimental factors for the cultural heritage. Furthermore the interaction with other long-term environmental factors (rainwater) as well as the impact of sudden environmental events (earthquakes, flood, landslides) may deteriorate more the geological conditions conducting to severe decays of historic buildings and monuments like cracks and partial or total building's collapses (Christaras, 2003; Gigli et al, 2012).

\subsection{Environmental impact on historic structures}

Long-term environmental factors affect both the preservation state and structural condition of the historic buildings and monuments provoking serious decays to them. In this paper the impact of the environmental agents at the structure of historic buildings and monuments will be presented. The examined buildings materials are timber, masonry and iron cast, which are the most common in historic buildings and monuments.

\begin{tabular}{|c|c|c|c|}
\hline IMPACT & HIGH & MEDIUM & LOW \\
\hline \multicolumn{4}{|c|}{ TIMBER } \\
\hline A1 & $\mathrm{XX}$ & $\mathrm{X}$ & \multirow{5}{*}{$\mathrm{X}$} \\
\hline A2 & $\mathrm{XX}$ & & \\
\hline A3 & & $\mathrm{X}$ & \\
\hline A4 & $\mathrm{XX}$ & $\mathrm{X}$ & \\
\hline A5 & $\mathrm{X}$ & $\mathrm{XX}$ & \\
\hline A6 & & & \multirow[t]{3}{*}{$\mathrm{X}$} \\
\hline A7 & $\mathrm{XX}$ & & \\
\hline A8 & $\mathrm{XX}$ & & \\
\hline \multicolumn{4}{|c|}{ MASONRY } \\
\hline A1 & \multirow{3}{*}{$\mathrm{X}$} & \multirow{3}{*}{$X$} & $\mathrm{X}$ \\
\hline A2 & & & $\mathrm{X}$ \\
\hline A3 & & & $\mathrm{X}$ \\
\hline A4 & \multirow[t]{3}{*}{$\mathrm{X}$} & \multirow{3}{*}{$\mathrm{XX}$} & $\mathrm{X}$ \\
\hline A5 & & & $\mathrm{X}$ \\
\hline A6 & & & $\mathrm{XX}$ \\
\hline A7 & $\mathrm{XX}$ & $\mathrm{X}$ & \\
\hline A8 & $\mathrm{XX}$ & $\mathrm{X}$ & \\
\hline \multicolumn{4}{|c|}{ CAST IRON } \\
\hline A1 & \multirow{3}{*}{$\mathrm{X}$} & $\mathrm{X}$ & \multirow[t]{8}{*}{$\mathrm{X}$} \\
\hline $\mathrm{A} 2$ & & $\mathrm{X}$ & \\
\hline A3 & & $\mathrm{X}$ & \\
\hline A4 & \multirow[t]{2}{*}{$\mathrm{X}$} & $\mathrm{X}$ & \\
\hline A5 & & $\mathrm{X}$ & \\
\hline A6 & $X$ & & \\
\hline A7 & $\mathrm{XX}$ & $\mathrm{X}$ & \\
\hline A8 & $\mathrm{XX}$ & $\mathrm{X}$ & \\
\hline & $\begin{array}{l}\text { less fre } \\
\text { more } \mathrm{f}\end{array}$ & $\begin{array}{l}\text { occurrences } \\
\text { nt occurrenc }\end{array}$ & \\
\hline
\end{tabular}

Table 3. Influence of long-term impacts on structural properties of building 
Many historic structures include timber as structural elements like timber beams, roofs, pillars or timber frames. Timber elements are usually in combination with other building materials, mostly with masonry, due to their ability to enhance the stability of the structure (Bagbanc1, 2013). On the other hand masonry (limestone, marble, granite etc.) is the most common building material in cultural heritage. From the ancient times people used masonry to for the construction of monumental buildings. Even though masonry is the most durable material through time, it shows significant susceptibility to environmental factors. Cast iron became very popular building material during the $19^{\text {th }}$ century. Cast iron's ability to carry more loads led its mass production and use to big structures as columns and ornamental parts of buildings (Davey, 2013).

Timber is the most vulnerable of the building materials. Environmental factors like the presence of insects and humidity can penetrate timber structures causing severe interior damage or extend already existing decays. Insolation causes brittleness, whilst geological conditions and loads threaten the building's stability. Regarding masonry, it shows great susceptibility to environmental impact but the decays are mainly on the surface of the buildings or in depth of millimeters (or maximum some centimeters). Therefore their impact leads to detachments and material loss but they don't cause great damage to the structure. Nevertheless the combination of long-term loads and the geological conditions with sudden events (earthquake, fire) as well as human impact (vandalism, war) could threaten the masonry structures. As far as iron cast is concerned, the environmental factors that affect it the most are its exposure to water (seawater and acid rainwater) and particle matters. Because of water's impact phenomena like rusting (oxidation) and graphitization are occurred. Depending on material's properties, components and the grade of its exposure to these factors, rusting can cause severe decay and even total loss of materials' components. Moreover the conversion of iron to soluble iron oxide and thus the historic structure is weakened (US-GSA).

In Table 3 an attempt to judgement of impact of the long-term environmental factor to the structural properties of historic structures is presented. The judgement is provisional and illustrative and is based on understanding of authors generated from their professional experiences. It should be understood as a suggestion for future assessments of impact of long-term processes to resistance of structures to natural disastrous actions.

\section{CONCLUSIONS}

Long-term environmental factors have a great impact on the Cultural Heritage by causing a variety of decays to the historic buildings and monuments. These decays are the outcome not of the development of only one environmental factor but rather of their interaction. Bio-attack implies the presence of water and solar radiation in order for microorganisms to be developed and colonize the building's surface. Particle matters and rainwater are in a direct interaction with the wind, which facilitate their deposition on the surface of into fissures and cracks. Geological formation, which threatens all the building materials above, can be influenced by rainwater and thus aggravate its instability.

Furthermore the environment seems to adjust to the changes occurred by human activities. The reduction of the vegetation at the area nearby monuments contribute to its exposure to environmental factors such as the solar irradiation (no protective shades by trees) and rainwater (no roots to hold the water underground), whereas industrial activities and transports contribute to the change of the world climate (rising of the greenhouse effect) with detrimental consequences to the cultural heritage.

The study of the impact of the long-term environmental factors is crucial for the protection of the cultural heritage. Challenges arise in order to understand their mechanism, how they interact with each other and also how their impact to cultural heritage is connected with accidental environmental events. Environmental influence to cultural heritage is a very demanding study field, which requires interdisciplinary (engineers, geologists, biologists, environmentalists etc.) and continuous monitoring of historic structures and their surrounding area. The comprehension of the decay mechanisms to historic structures caused by these factors as well as their interaction will contribute to the application of more compatible conservations interventions.

\section{ACKNOWLEDGEMENTS}

The on-going research work that is in background of this paper is supported by European Commission (EC) through the Initial Training Networks for Digital Cultural Heritage: Projecting our Past to the Future (ITN-DCH, FP7-PEOPLE-2013-ITN-MarieCurie Action: "Initial Training Networks" Project reference: 608013 funded under: FP7-PEOPLE From 2013-10-01 to 201709). The research is based on results of EC financed Coordinated Action EU-CHIC (FP7-ENV-2008-1 no. 226995, 2009/12). The authors acknowledge the support of European Commission to their research.

\section{REFERENCES}

Anzani A., Binda L., Mirabella Roberti G., 2000. The effect of heavy persistent actions into the behaviour of ancient masonry, Materials and Structures, Volume 33, Issue 4, pp. 251-261

Bagbanc1 M.B., 2013. Examination of the failures and determination of intervention methods for historical Ottoman traditional timber houses in the Cumalıkızık Village, BursaTurkey. Engineering Failure Analysis 35, pp. 470-479.

Bonazza A., Messina P., Sabbioni C., Grossi C.M., Brimblecombe P., 2009. Mapping the impact of climate change on recession of carbonate buildings in Europe. Science of the Total Environment, Volume 407, Issue 6, pp. 2039-2050.

Brimblecombe P., Grossi C.M., Harris I., 2011. Climate Change Critical to Cultural Heritage. Survival and Sustainability Environmental Earth Sciences 2011, pp. 195-205.

Christaras B., 2003. Engineering Geological Factors of Damage at Greek Monuments and Sites included in the World Heritage List of UNESCO. Technica Chronica (Technical Chamber of Greece), Volume 2, pp. 37-55.

Climate for culture - Damage risk assessment, economic impact and mitigation strategies for sustainable preservation of cultural heritage in the times of climate change, FP7-ENV-2008-1, no.: 226973; 2009/2014;

http://www.climateforculture.eu/index.php?inhalt=home

Davey A., 2013. Maintenance and Repair Techniques for Traditional Cast Iron-Short Guide. Historic Scotland, pp.2-4, 6, http://conservation.historic-scotland.gov.uk/publicationdetail.htm?pubid=9908. 
European Cultural Heritage Identity Card, EU FP7-ENV-20081 no. 226995; 2009/2012; http://www.eu-chic.eu

Feilden B.M., 2003. Conservation of Historic Buildings Third Edition. Architectural Press, Elsevier, Amsterdam, pp. 93-114.

Gaylarde C., Ribas Silva M., Warscheid Th., Microbial impact on building materials: an overview. Materials and Structures, Volume 36, Issue 5, pp. 342-352.

Gigli G., Frodella W., Mugnai F., Tapete D., Cigna F., Fanti R., Intrieri E., Lombardi L., 2012. Instability mechanisms affecting cultural heritage sites in the Maltese Archipelago. Natural Hazards and Earth System Sciences, 12, pp. 18831903.

Guidance on inventory and documentation of the cultural heritage, prepared by Ad hoc Group for inventory and documentation within the Technical Co-operation and Consultancy Programme, Council of Europe Publishing, Strasbourg, France, 2009 http://archives.icom.museum/object$\mathrm{id} /$ heritage /core.html

Harrell J.A., Broekmans M.A.T.M., Godfrey-Smith D.I., 2007. The origin, destruction and restoration of color in Egyptian travertine. Archaeometry Volume 49, Issue 36, pp. 421-43.

Hofmann F.G, Maxwell I., De Naeyer A. (editors), 2002. COST action C5: Urban Heritage - Building Maintenance: final report; EUR 20447; EC Directorate-General for Research, Brussels, 2002, 264 pages. http://bookshop.europa.eu/en/cost-action-c5pbKINA20447/?CatalogCategoryID=ANIKABstUgUAAAEjCJ EY4e5L

Hussein A.S., El-Shishiny H., 2009. Influences of wind flow paver heritage sites: A case study of the wind environment over the Giza Plateau in Egypt. Environmental Modelling \& Software, Volume 24, Issue 3, pp. 389-410.

Karoglou M., Moropoulou A., Maroulis Z.B., Krokida M.K., 2005. Water sorption isotherms of some building materials. Drying Technology, 23, Taylor and Francis, pp. 289-303.

Maravelaki-Kalaitzaki P., 2004. Black crusts and patinas on Pentelic marble from the Parthenon and Erechteum (Acropolis, Athens): characterization and origin. Analytica Chimica Acta 532, pp. 187-198.

Moropoulou A., Bisbikou K., Torfs K., van Grieken R., Zezza F., Macri F., 1998. Origin and growth of weathering crusts on ancient marbles in industrial atmosphere. Atmospheric Environment Vol.32, No 6, pp. 967-982.

Scheerer S., Ortega-Morales O., Gaylarde C., 2009. Microbial deterioration of stone monuments-an updated overview. Advances in Applied Microbiology, Volume 66, Elsevier, Amsterdam, pp. 97-139.

US-GSA. Historic Preservation - Technical Procedure, Cast Iron: Characteristics, Uses And Problems, U.S.A http://www.gsa.gov/portal/content/111738

Vodopivec B., Žarnić R., Tamošaitiene J., Lazauskas M., Šelih J., 2014. Renovation priority ranking by multi-criteria assessment of architectural heritage: the case of castles. International journal of strategic property management, Year 18 , No. 1, pp. 88-100.
Žarnić R., (ed.), Rajčić V., (ed.), Vodopivec B., (ed.). 2012, Heritage protection: from documentation to interventions, Proc. of the EU-CHIC International conference on Cultural Heritage preservation, 29 May - 1 June 2012, Split, Croatia. University of Zagreb, Faculty of Civil Engineering, $235 \mathrm{pp}$. http://eu-chic.eu/images/uploads/CHIC\%20Split\%20Conf\%20$\% 20$ proceedings $\% 20$ final.pdf

Žarnić R., Rajčić V., Moropoulou A., 2012 Identity card of cultural heritage: how to collect and organize data. Progress in cultural heritage preservation. Ed. Ioannides, M., 4th International Conference, Euromed 2012, Limassol, Cyprus, October 29 - November 3: proceedings, 1st ed. New York ... [etc.]: Springer, 2012, pp. 340-348. 